Hispania Sacra, LXVII

136, julio-diciembre 2015, 505-529 ISSN: 0018-215X, doi: 10.3989/hs.2015.015

\title{
SANTA TERESA EN LOS CONVENTOS DE MONJAS DE NUEVA ESPAÑA
}

\author{
POR \\ ASUNCION LAVRIN \\ Arizona State University
}

\section{RESUMEN}

El trasplante de la espiritualidad teresiana a Nueva España fue una experiencia que puso a prueba la capacidad de adaptar su mensaje reformista a las circunstancias de nuevas sociedades en formación en el imperio español. Con sólo siete conventos femeninos en el nuevo virreinato, la Orden logró seguir los preceptos esenciales de Santa Teresa aunque matizados por una religiosidad barroca que insistía en mortificaciones espirituales y corporales, completa humildad y obediencia, experiencias visionarias, e imitatio Christi para acceder al amor de Dios. A pesar de su corto número las Carmelitas ganaron el respeto de la sociedad colonial por su dedicación a la vida ascética, la pobreza personal y la centralidad de la práctica de la oración.

PAlABRAS ClAVE: Carmelo Teresiano en Nueva España; vocaciones y carisma teresianos; religiosidad barroca; penitencias, visiones y devociones.

\section{SAINT TERESA IN NEW SPAIN'S NUNNERIES}

\begin{abstract}
The transfer of the spiritual message of Saint Teresa to the viceregal court of New Spain tested the ability of Teresa's teachings to adapt to new societies within the Spanish empire. Although the Carmelites founded only seven convents in Mexico, the Order succeeded in following the key precepts of the Teresian charisma, although nuanced by a baroque style of observance that insisted on spiritual and corporal mortification, complete humility and obedience, visionary experiences, and the imitation of Christ to achieve God's love. Despite their small numbers, Carmelite nuns earned the respect of colonial society for their dedication to an ascetic way of life, personal poverty and the centrality of prayer.
\end{abstract}


KEY WORDS: Carmelo Teresiano en Nueva España; vocaciones y carisma teresianos; religiosidad barroca; penitencias, visiones y devociones.

\author{
Recibido/Received 30-10-2014 \\ Aceptado/Accepted 01-12-2014
}

En su niñez Santa Teresa quiso irse a otras tierras a convertir. Ya como reformadora de su orden salió de su convento muchas veces a fundar otros palomares para sus palomicas. Y, sin embargo, cuando recibió la petición para fundar un convento allende el mar no se sintió segura si aún era la hora para esa aventura física y espiritual.1 Es muy posible que tuviera toda la razón en su decisión. La petición para enviar monjas españolas al nuevo mundo parecería prematura cuando aún no estaba su reforma firmemente anclada en España. Pero para quienes abrazaron su reforma espiritual, la distancia geográfica y la falta de religiosas profesas españolas de quien aprender no fue óbice para seguir sus pasos. En Nueva España el primer convento carmelita de América se fundó en Puebla por bula pontificia en 1604 y recibió sus cinco fundadoras en 1606. En total, hubo siete conventos teresianos en el virreinato de Nueva España.2 El crecimiento de la orden fue relativamente lento. La expansión de otras órdenes femeninas menos austeras, con cabida para un mayor número de mujeres, y que daban la posibilidad de fundar patronazgos con privilegios personales ofreció una competencia formidable a las Carmelitas.

Aunque una historia detallada de esas fundaciones no pertenece en este trabajo, una revisión rápida de las mismas se hace necesaria. Los conventos novohispanos no recibieron monjas profesas de España. El arrastre de la interiorización de la vida espiritual, la atracción de la oración interior y el recogimiento que caracterizaron la espiritualidad propugnada por Francisco de Osuna y Luis de Granada y por la madre Teresa, anidaron en monjas novohispanas a través de la instrucción de los padres carmelitas de la provincia de San Alberto que llegaron a Nueva España en $1585 .^{3}$ La rama femenina de la

\footnotetext{
${ }^{1}$ Madre de Dios, Fr. Agustín de la. 1984. Tesoro escondido en el Santo Carmelo mexicano... México: Probursa y Universidad Iberoamericana, 211.

${ }^{2}$ Ramos Medina, Manuel. 1997. Místicas y descalzas. Fundaciones femeninas carmelitas en la Nueva España. México: Condumex; Sigüenza y Góngora, Carlos. 1683. Parayso Occidental... México: Juan Rivera; Gómez de la Parra, José. 1992. Fundación y primero siglo. Crónica del primer convento de carmelitas descalzas en Puebla, 1604-1704. México: Universidad Iberoamericana/Comisión Puebla $\mathrm{V}$ Centenario.

${ }^{3}$ Madre de Dios. 1984: 296. Este cronista atribuye la trasferencia de la esencia teresiana a Fray Pedro de los Apóstoles, prior del convento de Puebla que les dio las primeras constituciones.
} 
Orden se fortaleció con el apoyo de las autoridades episcopales, la Compañía de Jesús, tan cercana a la dirección espiritual teresiana, y la de los virreyes y otras órdenes religiosas. Por otra parte el reto carmelita atrajo no sólo a aquellas que pudieron profesar en el pequeño número de conventos, sino a mujeres que habiendo profesado en otras órdenes adoptaron algunos de los rasgos de las Carmelitas, no en sus reglas y constituciones sino en lo que se percibía como la herencia espiritual teresiana.

El primer Carmelo, fundado en Puebla, nació de un beaterio cuyas reglas fueron escritas por un rector jesuita de la ciudad de Veracruz y cuyas residentes leyeron la vida de Teresa proporcionada por un franciscano y siguieron la Regla adoptando el hábito carmelita. La comunidad se trasladó a Puebla en 1601. La instrucción de las religiosas estuvo a cargo de los Carmelitas poblanos aunque su gobierno quedó en manos de la sede episcopal. ${ }^{4}$ El convento de San José de México fue un desprendimiento del real convento concepcionista de Jesús María cuando un grupo de profesas decidió seguir una observancia más estricta de la vida conventual de acuerdo con el carisma teresiano. A pesar de la oposición de las Carmelitas de Puebla y de un visitador Carmelita opuesto a que monjas chocolateras y amigas de sirvientas fundaran otro convento de la Orden en la capital, la misma tuvo lugar en 1616 (dos años después de la beatificación de Teresa) con la ayuda de la virreina marquesa de Guadalcazar, que había vivido tres meses en un convento carmelita en España, y el apoyo del obispo Juan Pérez de la Serna. ${ }^{5}$ El convento de Guadalajara fue ideado por unas beatas peninsulares que habían vivido en Santo Domingo y llegaron a Nueva España en 1617. Lamentablemente la fundación no se efectuó sino hasta 1687, porque encontró tropiezos con el obispo de Guadalajara que se oponía al patronato único de la acomodada promotora del convento. El convento se fundó una vez que el patronato pasó a la iglesia episcopal y se nutrió de monjas poblanas. Un segundo convento teresiano en la capital recibió apoyo real en 1700 y se fundó en 1704 para suplir la necesidad de profesiones dado el número de aspirantes. El convento de Santa Teresa la Nueva-como se le llegó a conocer, contó con el apoyo financiero del convento de San José-ahora llamado «Santa Teresa la Antigua» y un rico protector, el capitán Esteban de Molina Mosquera. La hija única de Molina Mosquera y Manuela de la Barrera había profesado en San José, y pasó al nuevo convento como primera prelada. En Puebla se logró un segundo claustro en 1749 usando los mismos argumentos de necesidad de otro claustro para las vocaciones, y también apoyándose en el obispo Benito Crespo y las dignidades catedralicias, así como la promesa de un buen respaldo económico y la popularidad de la virgen de La Soledad, cuya iglesia fue apropiada

${ }^{4}$ Gómez de la Parra, J. 1992: 30-56; Madre de Dios. 1984: 294-96.

${ }^{5}$ Historia del convento de San José, por Mariana de la Encarnación. En Ramos Medina, M. 1997: 342. 
para el convento. El último Carmelo fue San José de Querétaro, fundado en 1803 con monjas de la capital, y nacido también de un beaterio que adoptó la regla teresiana. ${ }^{6}$ Este convento contó con el apoyo personal y económico de la marquesa de Selvanevada y varios patrones de la ciudad. El apoyo del virrey Miguel de la Grúa Talamanca selló la aprobación del Consejo de Indias.?

Ninguna de las fundaciones Carmelitas estuvo bajo la supervisión de la Orden. ${ }^{8}$ Las autoridades episcopales mantuvieron su control celosamente, a despecho de la incomodidad contra el mismo expresada en algunas ocasiones. A mediados del siglo XVII un grupo de monjas del convento de San José de México demandaba dirección espiritual de miembros de su Orden mientras la voz disidente de una religiosa se adhería a la dirección de un clérigo secular, tal y como era costumbre en tiempos de Teresa. La historia es compleja y comenzó en 1646 con una petición al rey de ponerlas bajo obediencia de sus hermanos de Orden. En 1652 repiten la petición y también escriben a la virreina duquesa de Alburquerque esperando simpatía y apoyo, lo que resultó que a través del tiempo hubo una facción virreinal frente a una facción arzobispal sobre este asunto. Durante un periodo de dos años las disidentes se vieron apoyadas por un efímero arzobispo y hasta el Consejo de Indias, pero con la llegada del arzobispo Mateo Sagade Bugueiro (1655-1663), un ferviente creyente en la autoridad episcopal, se reabrió la causa. La oposición entre la autoridad arzobispal y la virreinal, favorable a las monjas, caracterizó varias décadas de contenciosa argumentación. El proceso de disidencia se hizo más complejo con el inicio de una causa inquisitorial contra las peticionarias ya que se suponía que quienes promovían la dirección espiritual con miembros de su propio Orden sostenían proposiciones heréticas acerca de la autoridad episcopal. Elisa Sampson Vera Tudela subraya las tensiones étnicas del proceso con el intercambio de adjetivos despectivos entre los dos bandos ya que quienes proponían el regreso a la autoridad de la orden Carmelita eran «gachupinas», o sea, españolas de nacimiento. ${ }^{9}$ Nada se resolvió al respecto. Los arzobispos Osorio y Escobar

\footnotetext{
${ }^{6}$ Sigüenza y Góngora, C. $1683: 71,78 v, 79 v, 83 v-84,85 v$, 92. Inés de la Cruz escribió una crónica de la fundación del convento de México que Sigüenza y Góngora aprovechó. Ver Ramos Medina, M. 1997: 73-94, 313-330.

${ }^{7}$ Ramos Medina, M. 1997: 31-110.

${ }^{8}$ Agustín de la Madre de Dios comenta sobre lo deseable que fuera poner las almas de las religiosas en manos de Carmelitas pues mal las podían guiar quien no conocía la estrechez de la Orden. Subraya la fortuna de la madre Isabel de la Encarnación que pudo ser dirigida por su hermano en religión, Alonso de Jesús. Madre de Dios. 1984: 387.

${ }^{9}$ Sampson Vera Tudela, E. 2000. Colonial Angels. Narratives of Gender and Spirituality in Mexico, 1580-1750: 55-75. Austin: University of Texas Press; Ramos Medina, M. 1997: 149-68. Algunas cartas están reproducidas en págs. 262-67; Lavrin, A. 1995. «De su puño y letra: Epístolas conventuales» en M. Ramos Medina, El Monacato femenino en el imperio español: 43-59. México: Condumex. En las páginas 49-50 reproduzco una carta de la abadesa a la virreina. Ver comentarios de una capuchina peninsular respecto a monjas criollas en Lavrin, A. 1996. «La celda y el siglo. Epístolas conventuales»,
} 
(1664-1668) y Payo Enríquez de Ribera (1668-1681) mantuvieron su posición de autoridad contra viento y marea. Las Carmelitas poblanas aspiraron al mismo privilegio y a pesar de una opinión favorable del Consejo de Indias, el arzobispo Francisco de Aguiar y Seijas (1682-1698) no hizo cambio alguno. La rama femenina del Carmelo permaneció bajo autoridad episcopal por el resto del periodo virreinal.

Hubo otros casos de ejercicio de autoridad episcopal contra las Carmelitas. El obispo Juan de Palafox influyó en la elección de la poblana Mariana de Jesús Nazareno y luego la desposeyó de su oficio «por parecerle conveniente..$^{10}$ Una sonada causa fue la del arzobispo José Lanciego y Eguilaz (1713-1728) contra Juana María de San Esteban, prelada electa del convento de Santa Teresa «la Nueva» en la capital. En 1723 el arzobispo desaprobó la distribución de oficios de la nueva priora y la destituyó prohibiendo que se diera a conocer la situación fuera del convento. No se ha explicado el motivo de la conducta del eclesiástico. Evidentemente la noticia se esparció por la ciudad y el arzobispo tomó medidas enérgicas contra la monja, enviándola al convento de San José, de donde había salido a la nueva fundación. La pública protesta jurídica de la monja exacerbó el asunto que llegó hasta España y el Consejo de Indias e hizo renacer el deseo Carmelitano de independizarse de la autoridad episcopal. Lanciego y Eguilaz murió en 1728 y su sucesor Juan Antonio Vizarrón y Eguiarreta (1730-1747) envió a la madre San Esteban a Caracas a fundar un convento-asunto que no prosperó. Las monjas y sus compañeras regresaron a México en 1736 siendo recibidas con muestras de apoyo eclesiástico y secular. ${ }^{11}$ Como en España, la aspiración de espiritualidad en los escritos, avisos y recomendaciones de Santa Teresa pertenecen al plano del carisma, pero los asuntos del mundo crearon tensiones ex-claustro aunque no dañaron la percepción de los conventos como instituciones de rigurosa adherencia a una observancia piadosamente ascética.

\section{Las discípulas de Teresa de Jesús en Nueva España}

Considerando que al final del periodo virreinal había 57 conventos en Nueva España las fundaciones Carmelitas fueron una minoría numérica. Sin embargo, la influencia teresiana tiene que medirse en términos culturales, no fundacionales. Su huella se encuentra en el espíritu de interiorización, dedicación a la

en M. Moraña (ed), Mujer y cultura en la Colonia Hispanoamericana: 139-59, Pittsburg: Instituto Internacional de Literatura Iberoamericana, University of Pittsburg.

${ }^{10}$ Gómez de la Parra, J. 1992: 227, 234.

${ }^{11}$ Ramos Medina, M. 1997: 169-80. Para otros problemas de gobierno entre las religiosas novohispanas de varias órdenes, ver, Sampson Vera Tudela, E. 2000: 122-32; 275-309. 
oración, y la aceptación de humildad, obediencia y penitencia que representaron la cúspide de la espiritualidad femenina. ¿Qué motivaba a una mujer o a un grupo de ellas a fundar una réplica conventual teresiana en tierras adonde el cristianismo católico apenas había sido implantado? La historia nos llega mediada por las crónicas de esas fundaciones o por documentos oficiales que quizás de modo opaco pero confiable nos permitan analizar la vivencia de las seguidoras de Teresa en Nueva España.

Según se colige de los retazos autobiográficos de monjas teresianas incluidos en las crónicas y biografías oficiales, las vocaciones se alimentaron de la lectura de la biografía de Santa Teresa (posiblemente la de Fr Luis de León) y la guía de los primeros padres carmelitas a través de pláticas confesionales y sermones. También los jesuitas fungieron como contrafuertes en el apuntalamiento del desarrollo espiritual de las carmelitas. Sin embargo fueron las mujeres mismas quienes fundamentaron la orden con su promoción personal, a través de beaterios organizados espontáneamente, o de la convicción personal de otras que persistieron en la expansión fundacional. La primera en el grupo fundacional fue Marina de la Cruz (1536-1597), lega del real convento concepcionista de Jesús María y Carmelita en espíritu, aunque nunca vistió el hábito. Fue el pilar alrededor del cual se formó el núcleo del que saldría el convento de San José de la ciudad de México. Carlos Sigüenza y Góngora, cronista del convento, dedicó una tercera parte de su obra a las fundadoras carmelitas, Mariana de la Encarnación, Inés de la Cruz y especialmente Marina de la Cruz. Escribiendo nueve décadas después de la muerte de Sor Marina en 1597, Sigüenza no oculta su admiración por esta mujer, quien al parecer creía haber sido un avatar espiritual. Marina, nacida en España, conocía las propuestas fundamentales de la observancia carmelita cuando profesó en Jesús María y pronto las comenzó a poner en práctica, criticando ácidamente las «relajaciones» de las concepcionistas, practicando la humildad y buscando un retiro propio para sus oraciones y meditaciones. Habiendo profesado ya cincuentona y en calidad de lega no se le dio acceso al Coro. En esas condiciones de inferioridad social y espiritual, sus aspiraciones a una vida más estrecha le ganaron la animosidad de la comunidad. Marina se retiraba a una pequeña torre para alcanzar el silencio místico, «cuya quietud sirve de medio para que Dios nos hable» y pasó por el tamiz de cinco figuras eclesiásticas del más alto rango, dos dominicos y tres jesuitas. Sigüenza ofrece varios pasajes de escritos atribuidos a la religiosa en los cuales se detectan los temas de la imitación del sufrimiento de Cristo y la fe en el amor de Dios tanto en tribulaciones como en retribuciones, las comunicaciones con Teresa de Jesús, y el nacimiento de un mundo visionario que muy pronto caracterizó la espiritualidad femenina novohispana. Sabemos que Marina leía al padre agustino, Alonso de Orozco [1500-1591] y que conocía e imitaba la doctrina de Santa Teresa, a través de su vida, ya impresa y accesible en Nueva 
España. ${ }^{12}$ Sigüenza se dolía de la falta de reconocimiento de Sor Marina como verdadera discípula de Teresa y deseaba hacer ver a sus lectores cuan cerca había estado la religiosa del espíritu de la santa. Hay que tener en cuenta que ya para cuando Sigüenza escribía Teresa había sido canonizada y se conocían sus escritos ampliamente, no así cuando Marina escribía, lo que hace la labor de esta proto-Carmelita más meritoria. ${ }^{13}$

El deseo de rescatar la vida espiritual de las religiosas novohispanas que Sigüenza y Góngora representó fue compartido por otros clérigos en el siglo XVII. Sin embargo aunque fueron pocas las biografías y escritos de religiosas que vieron la luz en ese siglo la indagación llevada a cabo por los religiosos dejó varios testimonios de importancia: una biografía, datos personales incorporados a crónicas, y otros documentos fundacionales lamentablemente relegados a los archivos por muchos años. Es a través de ellos que se rastrea la huella teresiana y su carácter aunque nunca podremos escapar completamente del retoque de los originales por los confesores y biógrafos. La transformación del carisma teresiano en una observancia barroca post-tridentina comenzó durante la propia vida de Teresa y entre sus seguidoras. El meollo de la Orden y la herencia de Teresa eran oración, obediencia y pobreza a los que se unían «milagros y prodigios, éxtasis, revelaciones, visiones y favores de Dios, el don de profecía, el conocimiento de los interiores y otras gracias gratis dadas». ${ }^{14}$ En Teresa esos objetivos tuvieron una sobriedad formal y espiritual que podría llamarse «clásica.» A medida que sus pupilas y seguidoras comenzaron a experimentar con el «método» teresiano, el mensaje tomó las expresiones personales de las intérpretes. Era de esperarse que en el siglo XVII la teatralidad del lenguaje, la búsqueda de los contrastes emocionales, la aspiración a una experiencia espiritual intensa y desgarrante que pudiera impresionar a testigos presentes y lectores piadosos, hicieran que los objetivos y experiencias de otras monjas de la Orden se volvieran a veces túrgidos espectáculos de una religiosidad diferente a la

${ }^{12}$ Los párrafos atribuidos a Marina están citados en letra cursiva en la impresión y dicen provenir de su confesor. Sigüenza no especifica si Marina tenía una copia de la vida de Teresa sino que la imitaba ya que la conocía bien. Ver Sigüenza y Góngora, C. 1683: 80v-81.Ver, Orozco, A.. 1620. Confesiones del M.V.P Alonso de Orozco, de la Orden de San Agustín. Madrid: Viuda de Cosme Delgado; Gante, Fr. Francisco Antonio de. 1720. Vida del Venerable padre Fr. Alonso de Orozco. Madrid Juan Sanz. Orozco escribió tratados de confesión y reglas de vida cristiana y fue predicador real en las cortes de Carlos V y Felipe II.

${ }^{13}$ Sigüenza y Góngora, C. 1683 : 71, 78v, 79v, 83-84, 85v, 87, 88,92v, a manera de ejemplos. Sigüenza cita el texto completo del elogio de la vida de Marina de Pedro de la Mota y Escobar, su confesor, demostrando que no fue el único admirador de la religiosa. Ver, págs. 48-52v. Inés de la Cruz escribió una crónica de la fundación del convento que Sigüenza y Góngora aprovechó para su obra. Ver Ramos Medina, M. 1997: 313-330.

${ }^{14}$ De la Cruz, Pablo. 1685. Recopilación sumaria de la historia de la Orden de Nuestra Señora del Carmen... con los de la reforma que hizo la santa Madre, seráfica virgen y mística doctora Santa Teresa de Jesús. Madrid: Bernardo de Villa-Diego, 196. 
propuesta por Santa Teresa. Biografías, relaciones personales, y crónicas, se llenan de transverberaciones, ataques demoníacos, penitencias mórbidas y, sobre todo, milagros, y visiones descritas con todos los visos coloristas de pinturas y acciones de carácter teatral experimentadas como pan de cada día. Ya Elizabeth Teresa Howe en su estudio de la madre Ana de San Agustín, señala como a pesar de la imitación que le cupo como primera generación teresiana, y su respeto a la autoridad de la ya beatificada y canonizada Teresa, la personalidad de Ana es diferente y sus objetivos personales, así como en la expresión de su espiritualidad, la distinguen notablemente de la maestra. ${ }^{15}$ Isabelle Poutrin ha subrayado la diferencia entre la sobriedad de la primera ola visionaria de las carmelitas descalzas, específicamente la de Santa Teresa, y la exuberancia de la imaginación del siglo XVII. También José Luis Sánchez Lora ha señalado la truculencia y exageración del barroco espiritual. ${ }^{16}$ Sin embargo, los Carmelitas, al menos los que escribieron en Nueva España en el siglo XVII, se veían a sí mismos de modo diferente y estudiando su propia historia, encontraban que el carisma teresiano se expandía por todo el mundo sin defectos o variaciones radicales que hubieran ofendido a Santa Teresa.

Hay que plantearse el cambio de las expresiones de espiritualidad no ya como una transformación de la esencia de Teresa sino como expresiones de una cultura religiosa que heredó un meollo teresiano pero que, en realidad, no representaba ya la totalidad de su mensaje original sino que era una expresión sui generis de otra época. Lamentablemente tenemos muy pocas muestras de escritos de monjas profesas dentro del Carmelo novohispano. ${ }^{17}$ No es que carecieran de creatividad sino que el peso del voto de obediencia las obligaba a dejar sus escritos en manos de los confesores. Lo que podría parecer «cortedad de entendimiento... era humildad profunda» pues era un signo teresiano esconder las luces de la capacidad al mundo para dirigir al cielo los ardores del espíritu.$^{18} \mathrm{De}$

${ }^{15}$ Howe, E.T. 2004. The Visionary Life of Madre Ana de San Agustín: 1-41. Suffolk: Támesis.

${ }^{16}$ Poutrin, I. 1995. Le Voile et la Plume. Autobiographie et Sainteté Feminine dans l'Espagne Moderne : 93. Madrid: Casa de Velázquez; Sánchez Lora, J. L. 1988. Mujeres, conventos y formas de la religiosidad barroca. Madrid: Fundación Universitaria Española; Herpoel, S. 1999. A la zaga de Santa Teresa : autobiografias por mandato. Amsterdam, Rodopi ; Lavrin, A. y Loreto López, R. (eds.) 2006. Diálogos espirituales. Manuscritos Femeninos Hispanoaméricanos, Siglos XVI-XIX, Puebla : UDLA.

${ }^{17}$ Se han rescatado relaciones de fundaciones de mano de Inés de la Cruz y Mariana de la Encarnación. Ver Ramos Medina, M. 1997: 313-369. Loreto López, R. 2002. «Escrito por ella misma. Vida de la madre Francisca de la Natividad.», en A. Lavrin y R. Loreto López (eds.) Monjas y beatas. La escritura femenina y la espiritualidad barroca novohispana. Siglos XVII y XVIII. Puebla: Universidad de las Américas, México/ Archivo General de la Nación.

${ }^{18}$ Gómez de la Parra, J. 1992: 367. Al respecto ver, Baranda Leturio, N y Marín Pina, Ma C. 2014. «El universo de la escritura conventual femenina: Deslindes y perspectivas», en Letras en la celda. Cultura escrita de los conventos femeninos en la España moderna: 11-45. Madrid/Frankfurt: Iberoamericana/Vervuert.

Hispania Sacra, LXVII

136, julio-diciembre 2015, 505-529 ISSN: 0018-215X, doi: 10.3989/hs.2015.015 
sus testimonios se hicieron cargo sus cronistas e intérpretes y sus experiencias nos llegan a través de ese tamiz histórico y reinterpretativo. ${ }^{19}$

En el paso del Atlántico a la Nueva España la convivialidad de los seres divinos, la presencia del demonio y sus huestes, y las aventuras de las religiosas en los espacios celestiales se convierten en una parte muy relevante del «mensaje» de la espiritualidad femenina, no solo en el Carmelo sino en el resto de las órdenes religiosas. Las visionarias asumen el protagonismo de la palabra escrita - por mano propia o como objetos de crónicas y biografías- y de la sociabilidad que emana de los claustros y se derrama en las calles de los centros urbanos virreinales. No cabe duda que la inspiración teresiana se encontraba viva en las religiosas novohispanas, pero tampoco cabe duda que fue reinterpretada y acomodada a la necesidad personal de aquellas de quienes conocemos algunos escritos, o de quienes se escribió como modelos ejemplares.

\section{LAS HUELLAS EN LA OBSERVANCIA}

El más importante legado teresiano fue el de sus Reglas y la observancia de las mismas en sus conventos. La certidumbre de seguir las reglas tal y como se observaban en España y como las había diseñado Teresa fue el motivo de mayor orgullo en las comunidades novohispanas y sus cronistas. También persuadió a mucho laicos que respetaban y apoyaban a las Teresas. El padre de Teresa del Costado de Cristo no cesó de persuadir a su hija ser monja Carmelita hasta que la misma profesó en las Teresas poblanas.$^{20}$ Como vimos con los incidentes del convento de San José en México con los arzobispos, esa observancia encontró escollos, pero la historia apologética de la orden en manos de sus cronistas nos llevan a otros rumbos al acentuar las virtudes de las religiosas ejemplares. No es de dudar que en materia devocional comunitaria y personal, las religiosas se acercaran lo más posible al espíritu de observancia de su tiempo. Una innovación que introdujeron para reforzar su instituto fue el voto de no tomar chocolate para refutar las objeciones de quien las había tildado de monjas chocolateras. Este voto fue tomado muy en serio por las Teresas pero parece haber perdido algunas devotas. En 1735 la madre Josefa de San Miguel, trasladada del convento de San

\footnotetext{
${ }^{19}$ Salmerón, Pedro. 1675. Vida de la Venerable Madre Isabel de la Encarnación. México: Francisco Rodríguez Lupercio. Aquí uso la versión moderna editada por Robin Ann Rice, 2013. Madrid: Iberoamericana/Vervuert. Salmerón utilizó dos biografías inéditas de la madre, una escrita por Miguel Godínez, S.J. y otra por Fr. Agustín de la Madre de Dios. Este último sintetizó la vida de la religiosa en su crónica sobre la Orden del Carmen en Nueva España. Ver, Madre de Dios. 1984: 312-343.

${ }^{20}$ Gómez de la Parra, J. 1992: 260-61. La vocación de la joven era para las Concepcionistas pero entró en San José para complacer a su padre. Sin embargo tras varias experiencias visionarias corroboró su vocación teresiana.
} 
José de México al de Santa Teresa la Nueva, solicitó ser devuelta a su convento cuando comprobó que se había roto el voto de abstención de chocolate durante una profesión y que los prelados estaban dispuestos a rescindir el voto «por no ser en esta tierra para que se pueda mantener en ella la religión Carmelita, si no es a fuerza de dispensar...». ${ }^{21}$ En realidad, esta disidencia no fue representativa y la estrechez de la Orden se mantuvo a través del tiempo. En Puebla se tenían las obras de Teresa y San Juan de la Cruz como guía espirituales, pues así lo delinea Gómez de la Parra al ir citando la doctrina de Teresa en sus diversos libros. El cronista también recomendaba la lectura de las anotaciones de Santa Teresa escritas por Juan de Palafox. ${ }^{22}$ Gómez de la Parra dedica varios apartados de su crónica a elogiar la observancia en el convento de Puebla. ${ }^{23}$ La primera virtud que poseían las religiosas -escribe-era la de la oración, el más poderoso legado teresiano vinculado a su Camino de Perfección. La comunidad siempre tenía alguna religiosa en oración en su coro. Todas las semanas se hacía un Vía Crucis mientras otras hacían las estaciones de María la Antigua. Las oraciones de viernes eran de rigor, y asimismo uno o dos ejercicios espirituales anuales. Estas y otras oraciones mentales resultaron, según el piadoso cronista, en que la mayoría de las treinta y seis religiosas que habían muerto durante el primer siglo de fundación habían alcanzado la contemplación sobrenatural con éxtasis y arrobamientos. Para finales del siglo xvII, la expectativa de revelaciones y arrobamientos era parte de la normativa espiritual teresiana en el virreinato.

La mortificación era la segunda característica de la observancia. Entendida como hermana de la oración y producto del amor a Dios, cubría una amplia gama de mortificaciones corporales y espirituales. El examen diario de la conciencia se seguía rigurosamente en Puebla porque, nos asegura Gómez de la Parra, la contemplación unitiva solo podía conseguirse con el dominio de las pasiones y el cuerpo. Parte de la mortificación interior era la humildad que se interpretaba como la completa sumisión a los prelados y a la Prelada conventual y se suponía descendía directamente de Santa Teresa. La voluntad no podía quedar libre; era sometida a la humillación tanto comunitaria como personal y a la única voluntad aceptable, que era la de Dios. La pobreza era patente en la falta de adornos de las celdas y la renuncia a posesión alguna en las religiosas.

${ }^{21}$ Ramos Medina, M. 1997: 275-76. La monja creía que era posible ser Carmelita en México sin ninguna dispensación de la observancia y, a su modo, criticaba al arzobispo Vizarrón y Eguiarreta.

${ }^{22}$ Palafox y Mendoza, Juan. 1752. Obras, Tomo VII. Notas a las Cartas y Avisos de Santa Teresa de Jesús y varias poesías espirituales del venerable autor. Madrid: Imprenta de Gabriel Ramírez. Palafox escribió esas notas en 1656 a pedido de los carmelitas de Osma. Los comentarios eran conocidos en Nueva España. Palafox elogia la caridad, suavidad, dulzura, gracia y entendimiento -entre otras cualidades - en Santa Teresa, y explica el contenido de una selección de sus cartas. Palafox fue admirador de las Teresas poblanas.

${ }^{23}$ Gómez de la Parra, J. 1992: 89-123.

Hispania Sacra, LXVII

136, julio-diciembre 2015, 505-529 ISSN: 0018-215X, doi: 10.3989/hs.2015.015 
El segundo cronista Carmelita, Fr. Agustín de la Madre de Dios, comenta hiperbólicamente las virtudes y perfecciones de los varones carmelitas en la Nueva España, que atestigua vio y vivió como miembro de la comunidad. ${ }^{24}$ Respecto a las fundadoras de San José en México, Marina de la Cruz y Mariana de la Encarnación, dice que aprendieron intuitivamente leyendo la vida de Teresa. Reclutando otras compañeras se instituyó la observancia con la explicita aprobación de visiones de Cristo y Teresa de Jesús a falta de autoridades humanas superiores. Sin embargo, tenían a mano los modelos vivos de los Carmelitas fundadores, quienes se ejercitaban en una vida descrita por el autor como completamente ascética, lo que explica el tipo de disciplina y observancia de los conventos femeninos. Con padres tan alimentados «de los pechos de nuestra madre Teresa... no les hicieron falta fundadoras primitivas. $\nu^{25}$ Los padres les enseñaban «mortificaciones y penitencias, en la oración y retiro, el orden que habían de tener para el tiempo de los ejercicios de la ermita o celda... el de la negación de sus quereres y abstracción de las criaturas, el estilo de las mortificaciones de nuestros refectorios, que con tanto aprovechamiento conserva nuestra reforma.» ${ }^{26}$ Entre las monjas de Puebla también se reconoce la mano de Miguel Godínez S.J. en la dirección espiritual de varias fundadoras y monjas eminentes. ${ }^{27}$

¿Qué huellas de Santa Teresa encontramos grosso modo en las crónicas y biografías de monjas novohispanas? José Gómez de la Parra y Fr. Agustín de la Madre de Dios nos presentan a un grupo singularísimo de religiosas que durante el siglo XVII ejemplificó la observancia teresiana para la sociedad novohispana. Sus fuentes fueron, en parte, cuadernos escritos por sus hermanas en religión a instancias de Miguel Godínez, y testimonios orales y escritos de otras religiosas como la fundadora Melchora de la Asunción, que proveyó con largueza materiales de archivo para satisfacer la curiosidad de los cronistas. El licenciado Pedro Salmerón escogió a Isabel de la Encarnación, del convento de Puebla, para testimoniar en una vida, lo que en el siglo XVII novohispano se consideraba la impronta teresiana. Su biografía exaltaba la memoria de la monja y de la Orden con la esperanza de fomentar su beatificación. Las virtudes que elogiaba fueron la humildad, la obediencia, la paciencia, el amor a Dios y a sus prójimos, sus oraciones por las almas del purgatorio, y la oración y contemplación, a través de las cuales recibió grades mercedes de Dios. La persecución de los demonios le ocasionó enormes y constantes sufrimientos que padeció resignadamente, ayudada por las devociones que tuvo al santísimo sacramento, la pasión de Cristo

\footnotetext{
${ }^{24}$ Madre de Dios. 1984: 38-76.

${ }^{25}$ Madre de Dios. 1984: 211-14, 296.

${ }^{26}$ Madre de Dios. 1984: 214.

${ }^{27}$ Loreto López, R. 2006 «Oir, ver y escribir. Los textos hagio-biográficos y espirituales del padre Miguel Godínez. Ca 1630», en A. Lavrin y R. Loreto López (eds.): 156-200.
} 
y la reverencia y amor a María. ${ }^{28} \mathrm{La}$ observancia sin miedo, esto es, abrazada plenamente, fue elogiada en un sermón de profesión en San José por Fr. Pedro de Borges, quien también se extendió sobre el recogimiento del claustro, y la esclavitud al ejemplo de María, que llevaría la religiosa a aceptar la sujeción sin arbitrio. ${ }^{29}$

Ahora bien, ¿qué se entendió por observancia «sin miedo»? Es un punto de interés para comprender las «virtudes» que se ensalzan en las Carmelitas novohispanas. En el sermón del padre Borges se destacan las mortificaciones de la vida del Carmelo, un tema que se impuso como clave de la observancia teresiana en el siglo XVII. La regla primitiva y constituciones de los descalzos del Monte Carmelo tenían penas específicas para culpas incurridas en el comportamiento de los frailes. ${ }^{30}$ Se inspiraban en las palabras de San Bernardo sobre la necesidad del castigo a las transgresiones porque la impunidad fomentaba la reincidencia y la impureza. Las penitencias comunitarias se dirigían a avergonzar a los transgresores, provocar el arrepentimiento y el retorno a la observancia. Después de la contrición se podían incluir castigos corporales además de ayunos y aún encarcelamiento dentro del convento. Los conventos femeninos tenían reglas similares en su objetivo de mantener la disciplina interior. ${ }^{31}$ En sus Constituciones dadas en 1568 pero no impresas sino hasta 1596, Teresa discurre sobre el castigo de las culpas en comunidad una vez a la semana. Las formas de penitencia se dejaban a discreción de la Presidenta y consistían en oración, ayuno, y «disciplina» corporal en las espaldas. ${ }^{32}$ Por otra parte, en sus Avisos, Teresa recomienda a la religiosa andar siempre con grandes deseos de padecer por Cristo en cada cosa y ocasión y que «jamás deje de humillarse y mortificarse hasta la muerte en todas las cosas.» Además la religiosa «con todos sea mansa y consigo rigurosa» En tiempos de tristeza y turbación no debía dejar ni la oración ni la penitencia. El mensaje es suficientemente ambiguo para oscurecer la naturaleza de la «penitencia» pero en ese pequeño conjunto de reglas estaba la semilla de las prácticas que se señalaban como «propias» de la orden Carmelita en crónicas y biografías de los siglos XVII. Los conceptos de humillación, mortificación y penitencia, llevaron a algunas Teresas a actos devocionales

\footnotetext{
${ }^{28}$ Salmerón, P. 2013: passim.

${ }^{29}$ Borges, Fr. Pedro de. 1673. Sermón que predico a la profesión de la madre María de la Encarnación, religiosa descalza del convento de Santa Teresa de Jesús de esta ciudad. México: viuda de Juan de Robles.

${ }^{30}$ Regla Primitiva de los religiosos descalzos de la Orden de Nuestra Madre Santísima ... del Monte Carmelo de la Primitiva Observancia. 1788: 503-542. Madrid: Imprenta de D. Joseph Doblado. La penitencia personal de que tratamos era aquella impuesta por el confesor o asumida voluntariamente por el o la religiosa en acto de contrición.

${ }^{31}$ Ibídem, 209-252.

${ }^{32}$ Escritos de Santa Teresa. 1864. Vicente de la Fuente, ed. Tomo Primero. Madrid: M. Rivadeneira, Impresor, 273-80, 285-87.
}

Hispania Sacra, LXVII

136, julio-diciembre 2015, 505-529 ISSN: 0018-215X, doi: 10.3989/hs.2015.015 
de auto-flagelación y renuncias de comodidades que otras religiosas no teresianas pero en búsqueda de mayor observancia también adoptaron con gran brío y el aplauso de confesores y cronistas. ${ }^{33}$ Es preciso aclarar que en otras religiones como las clarisas y las capuchinas también se adoptaron prácticas de mortificación personal que sugieren que la piedad barroca se nutría de la noción de la necesidad de someter el cuerpo al espíritu y que la aspiración a la perfección en esta batalla era pasto espiritual común. ${ }^{34}$

Teresa no parece haber sido amiga de disciplinas corporales heroicas. En el Camino de Perfección explica el sufrimiento como algo personal e íntimo: «Sabed sufrir un poquito por amor de Dios, sin que lo sepan todos. $»^{35}$ Aprueba las mortificaciones públicas, pero avisa contra la mala interpretación de las penitencias. La discreción en la adjudicación personal y comunitaria de las penitencias era muy recomendable para evitar las ansiedades de confesores que temían las religiosas se mataban con penitencias, «y está aborrecida de nosotras esta falta de discreción.... ${ }^{36}$ Teresa no deseaba enfermedades y procuraba la salud de sus discípulas pero ambiguamente sugiere que si el demonio amedrentara con la falta de salud nunca se haría nada. De hecho, las enfermedades eran una forma de penitencia. Siempre hubo una tensión entre quitar el regalo del cuerpo y decidirse a morir por Cristo, y la aversión a disciplinas que quitaran la salud y que no eran deseables porque impedían la buena marcha de los conventos. Santa Teresa y sus discípulas habían sido educadas en la ascética de hombres como Luis de Granada que veían en la dominación del cuerpo por el espíritu uno de los objetivos de la vida virtuosa. También la Imitatio Cristi, que resurgió en el siglo XVI, alentaba la imitación de la pasión de Cristo. El dolor de Jesús se debía vivir en carne propia y ningún extremo era suficientemente

\footnotetext{
${ }^{33}$ Faci, R.A. 1761. Vida de la V. Mariana Villalba y Vicente y sus tres hijas Sor María, Sor Margarita y Sor Mariana de Escobar: 496. Pamplona: Pascual de Ibáñez. El Carmelita Faci pinta a estas tres monjas como modelos de vida penitente y austera. Refiriéndose a las disciplinas que se ejercitaban en el siglo XVII comenta que tales prácticas no hacían novedad entonces, aunque eran causa de rubor por la tibieza del siglo en que escribía [siglo XVIII].

${ }^{34}$ Lavrin, A. 1999. «La religiosa real y la inventada: diálogo entre dos modelos discursivos», en La Creatividad femenina en el mundo barroco hispánico. María de Zayas-Isabel Rebeca Correa-Sor Juana Inés de la Cruz: 535-552. Editado por Monika Bosse, Barbara Potthast y André Stoll. Kaseel: Edition Reichenberger.; Lavrin, A. 1995. «Espiritualidad en el claustro novohispano del siglo XVII», Colonial Latin American Review, 4:2, 155-180.

${ }^{35}$ Teresa de Jesús, 1752. Libro llamado Camino de Perfección. En Obras de la Gloriosa Madre Santa Teresa de Jesús, Tomo I. Madrid: Joseph de Orga, 446. También en Las Moradas escribe sobre las penitencias corporales como ineptos ejercicios de muchas que no tienen descanso si no se están atormentando. Ver, Teresa de Jesús. 1604. Libro llamado de las Moradas en Libros de la B. Madre Teresa de Jesús. Nápoles: Constantin Vidal, 19.

${ }^{36}$ Teresa de Jesús, 1752, 443-444. Criticaba Teresa a quienes les daba «un frenesí de hacer penitencias sin camino ni concierto» ya que eran prácticas a veces efímeras. Teresa buscaba el justo medio, y en fin de cuentas se ponía a la merced del Señor en cuanto a tener luz para acertar en todo.
} 
meritorio para igualar lo que Él había sufrido por nosotros. Ya para finales del siglo XVI las disciplinas personales comenzaron a hacerse exageradas y teatrales. ${ }^{37}$ Así nacieron generaciones de religiosas que se dedicaron a macerar sus cuerpos como atletas del martirio personal. La práctica se hizo de rigor entre las más devotas tanto en la península como en Nueva España y se hizo rasero para medir la «santidad» y virtud de las practicantes. La disciplina corporal se vio como medicina para curar varios aspectos de la debilidad humana y aun para redimir las culpas de otros. En el convento de San José de Puebla, como en todo establecimiento recién fundado, las disciplinas corporales y espirituales se ejercían con todo rigor en imitación de lo que creía era ejercicio usual de Teresa. Algunas se disciplinaban cinco veces al día. Los ayunos y las comidas sin sazón, o sazonados con chinches, las piedras en las alpargatas, las humillaciones personales en el refectorio, las procesiones con cruces a cuestas, las bofetadas en los rostros y otros ejercicios penitenciales eran tenidos por ocupaciones dignas de ganar el cielo y, sobre todo, idóneos del espíritu carmelita. Al parecer, estas disciplinas fueron moderándose, pero quedaron como ejemplo para las siguientes generaciones que siguieron ejercitándose en el uso de cilicios y las disciplinas de sangre aunque no tan intensamente como las prácticas degradantes de las fundadoras ${ }^{38}$ Por otra parte la relativamente breve narrativa de la vida de la poblana Francisca de la Natividad, carece de la truculenta descripción de penitencias corporales que encontramos en los cronistas, explicando ella que sus sufrimientos son originados por el cumplimiento de sus deberes conventuales. ${ }^{39}$

En Nueva España los cronistas teresianos del siglo xvII se desbordan en sus elgios de la disciplina corporal como especialidad de la Orden del Carmelo y como medio indispensable de alcanzar los más altos grados de espiritualidad conventual. Gómez de la Parra escribió que el concepto de padecer atraía a la orden carmelitana porque «mortificación y penitencia «eran su especialidad.» Así las religiosas poblanas, enfermas o saludables, «acometían contra su inocente cuerpo como si fuera delincuente, con ásperas y largas disciplinas,»... «con la aprobación de superiores y de sus compañeras de convento.» ${ }^{40}$

${ }^{37}$ Lanuza, M.B de. 1638. Vida de la bendita madre Isabel de Santo Domingo, compañera de Santa Teresa de Jesús: 355. Madrid: Imprenta del Reino. Fue fundadora del convento de San José de Zaragoza y de ella escribió su biógrafo que «siendo Priora de Pastrana, usó de este ejercicio: que a imitación de Christo mandaba que la atasen a un poste y la azotasen las religiosas hasta que la dejaban bañada (toda) cubierta de su sangre... Supo Santa Teresa este modo de penitencia que causaba horror a las hermanas y «mandó que no lo usase.»

${ }^{38}$ Gómez de la Parra, J. 1992: 93-96. Las primeras preladas y maestras novohispanas ejercieron una disciplina rigurosa en un deseo de seguir fielmente el legado teresiano, especialmente el de la oración y silencio. Ver Gómez de la Parra, J. 1992: 230-31, 233.

${ }^{39}$ Loreto López, R. 2002. «Escrito por ella misma.» Ibídem.

${ }^{40}$ Gómez de la Parra, J. 1992: 239-277. 
Delincuente, bruto, vil, despreciable y asociado con los pecados y las artimañas del demonio, el cuerpo pertenecía a la categoría de lo inferior mientras que la voluntad y el conocimiento representaban los planos superiores. El biógrafo de la ya citada Isabel de la Encarnación, asume que «la virtud que no está acompañada con penitencias y mortificaciones es sospechosa. $\gg^{41}$ De hecho Isabel profesó en el Carmelo poblano por entender que en esa religión había mucha penitencia y mortificación de acuerdo con las reglas escritas por la «santa madre Teresa.» Salmerón describe puntualmente sus disciplinas en el coro; como llevaba a cuestas una cruz en las espaldas con una corona de espinas, y como se ponía gotas de cera ardiente en los brazos y otras partes del cuerpo y se cubría el cuerpo de cilicios. ${ }^{42}$ Isabel también practicaba otras formas de comportamiento como parte de disciplina del Carmelo, como la abstención de alimentos, frecuentemente citada por los cronistas como prevalente entre las monjas ejemplares. Salmerón elogia el Carmelo escribiendo que era «una religión que profesa tanta penitencia y mortificación,» considerando sus enfermedades y trabajos corporales y espirituales, como parte de la observancia y galardón de una vida elogiable. ${ }^{43}$ No cabe duda que esta interpretación de la penitencia corporal como parte del concepto de mortificación era la respuesta a una mentalidad en la cual el cuerpo penitente se ofrecía a los lectores como objeto de meditación, mientras que la práctica dentro del convento era un compromiso personal de la penitente con lo que creía ser la más perfecta forma de contrición. Estos extremos en la ejecución de la disciplina y la obediencia quedaron en la memoria comunitaria y personal de aquellas que eligieron seguirlos y que persistieron en esas prácticas hasta el siglo XVIII. ${ }^{44}$

La disciplina personal y comunitaria tenía el elevado fin de acceder al amor de Dios y las finezas de su esposo Jesús. Gómez de la Parra afirmaba que era doctrina de Santa Teresa que las almas abrasadas del fuego del amor divino no hallaban quietud si no sufrían por su amado. Esta convicción estaba tan arraigada que pone de ejemplo de cómo lograr la perfección a través de la observancia, la humildad y la oración, a una donada negra del convento de Puebla, Esperanza de San Alberto, cuya vida fue tan ejemplar en abstinencias y amorosos fervores que la comunidad pidió la concesión del hábito para ella, rompiendo fuertes

${ }^{41}$ Salmerón, P. 2013: Cap. VII, 149.

${ }^{42}$ Salmerón, P. 2013: 150-153.

${ }^{43}$ Salmerón, P. 2013: 109 149-53. Dedica dos capítulos a los actos de penitencia y mortificación de Isabel de la Encarnación. Mortificación se entendía como un acto de humillación, mientras penitencia o disciplina invocaba agresión al cuerpo. No todas las biografías de monjas teresas se regodean en la descripción de disciplinas. Ver, Torres Villarroel, Diego de. 1798. Libro segundo. Vida ejemplar de la venerable madre Gregoria Francisca de Santa Teresa: 125-126, 217. Madrid: Imprenta de la Viuda «de Ibarra.

${ }^{44}$ Gómez de la Parra, J. 1992: 199-200, 265, 357, 
tradiciones contra la profesión de mujeres de origen africano.$^{45}$ La donada era muestra irrefutable de cómo Dios premiaba a los humildes y a todos los que se ofrecían incondicionalmente a su voluntad y sabían aceptar tanto sus pruebas como sus expresiones de amor dentro de la Orden del Carmelo.

Las visiones, esas escapadas afectivas a los ámbitos del espíritu fueron tan aceptables como comunes en el siglo XVII y aun el XVIII, y las Teresas novohispanas las compartieron plenamente. La visión barroca, en opinión de Sánchez Lora, fue la culminación de la teatralidad hagiográfica ${ }^{46}$ En esa teatralidad había mucho de finalidad didáctica. El imaginario religioso del siglo XVII dependía de la visión como fuente nutricia de la fe. El encuentro y la sociabilidad familiar con los seres divinos inyectaron visos de una realidad tangible por lo cotidiano de lo que era un plano divino fuera del alcance humano. El acceso personal al entorno del cielo -o el purgatorio y el infierno-fue la el don más deseado en quienes vivieron la vida claustral ${ }^{47}$ Esas vistas, inaccesibles a otros seres menos cercanos a la gracia de Dios, señalaban a quienes las recibían como testigos de la existencia del mundo celestial al que todo buen cristiano deseaba acceder. Quienes fueron declaradas como poseedoras de este don, se convirtieron en los íconos de sus comunidades y de su Orden, al ser receptoras y trasmisoras de gracias y poseedoras de una forma de sabiduría de lo divino que se comunicaba a través del arrobo y la visión. ${ }^{48}$ Las visiones no fueron siempre conocidas fuera de los muros claustrales; sólo con la impresión y publicación de crónicas o biografías se alcanzaba un público más amplio para las mismas. En el siglo XVII las Teresas novohispanas sólo tuvieron dos crónicas y una biografía donde recoger su mundo visionario, pero no debe descontarse la trasmisión oral de los fieles, siempre abiertos a esparcir noticias que les llegaban del interior de los conventos. ${ }^{49}$ Sobre todo, si Teresa había experimentado arrobamientos y visiones, sus discípulas también las querían para sí, y las llegaron a tener. Había algo igualatorio y hasta democrático en la experiencia visionaria que entre religiosas vivas ya no era experiencia exclusiva de los santos.

${ }^{45}$ Gómez de la Parra, J. 1992: 308-21. Este cronista gustaba de citar a Santa Teresa textualmente, añadiendo sus propios comentarios y convirtiendo su crónica en una obra de predicación y explicación del carisma teresiano.

${ }^{46}$ Sánchez Lora, J.L. 1988: 427.

${ }^{47}$ von Wobeser, G. 2011. Cielo, infierno y purgatorio durante el virreinato de la Nueva España. México: UNAM/Editorial Jus.

${ }^{48}$ Lavrin, A. 2009. «El más allá en el imaginario de las religiosas novohispanas», en G. von Wobeser y E. Vila Vilar, eds. Muerte y vida en el más allá. España y América, Siglos XVI-XVIII. México: UNAM.

${ }^{49}$ Para otros testimonios de visionarias novohispanas, ver, Gómez, Fr Joseph, 1689. Vida de la venerable madre Antonia de san Jacinto... hija del real... convento de santa Clara de Jesús... de Querétaro. México: Imprenta de Antuerpia; Pardo, Francisco. 1676. Vida y virtudes heroicas de la madre María de Jesús,... en el convento de la Limpia Concepción de la Virgen María... de los Ángeles.. México: Viuda de Calderón; Lavrin, A. 2005. «La madre María Magdalena Lorravaquio y su mundo visionario», Signos Históricos, 13: 22-41.

Hispania Sacra, LXVII

136, julio-diciembre 2015, 505-529 ISSN: 0018-215X, doi: 10.3989/hs.2015.015 
Gómez de la Parra sabía la diferencia entre visión y experiencia unitiva ya que afirma que la madre Francisca de la Natividad había llegado a «supremo grado de contemplación unitiva.» ${ }^{50}$ También Salmerón habla de la pérdida del uso de los sentidos de Isabel de la Encarnación y de cómo Dios le comunicaba a los «altísimos secretos de los misterios de nuestra fe». En esos «actos unitivos» parecía «se hacía una misma cosa con Dios.» ${ }^{51}$ Sin embargo, la mayoría de las visiones de las crónicas que cita son escenificaciones de encuentros con personajes divinos que ilustran el maridaje de la vista con la elevación espiritual. Lo que se veía y se narraba como tal, aun cuando se suponía era con los ojos el alma, se recordaba mejor y servía plenamente los fines didácticos de las hagiografías. Jesucristo y María fueron los más frecuentes protagonistas en la visiones de las Teresas, pero la santa apareció con frecuencia a sus discípulas novohispanas en momentos en que necesitaban consuelo e inspiración..$^{52}$ Dos de las monjas fundadoras vieron al padre Miguel Godínez, su confesor, en vida y después de su la muerte. El apego al director espiritual y el deseo de verlo en la gloria no fue únicamente teresiano, pero nos recuerda la fuerte relación de Teresa con el padre Gracián.

Además de las visiones personales deben mencionarse las apariciones o portentos asociados con Santa Teresa y Cristo que extendieron esos fenómenos fuera del claustro. El culto teresiano necesitaba de experiencias compartidas en el entorno urbano por la población secular. Esas apariciones extraordinarias que iban más allá de lo personal, tuvieron una base devocional basada en una reliquia del corazón de Teresa enviada al convento de Puebla por el padre general José de Jesús María..$^{53}$ En 1618 la reliquia comenzó a generar visiones de Teresa, de Cristo, la Virgen y el niño Jesús, la Trinidad y otros personajes. Este fue el primer objeto devocional que satisfizo con abundancia la necesidad de sacralizar los espacios de los recién fundados conventos y de fomentar el culto teresiano. ${ }^{54}$ La reliquia del corazón de Teresa fue el gatillo detonador de las visiones poblanas elocuentemente narradas por fray Agustín de la Madre de Dios. En esa narración se advierte ya la adopción del realismo visionario que caracterizara la religiosidad hispana y novohispana.

En Puebla, un portento atribuido a Santa Teresa fue la confección de unos panecitos que sirvieron para aumentar la devoción de los fieles. La madre Melchora de la Asunción - primera generación de fundadoras - tuvo una visión

\footnotetext{
${ }^{50}$ Gómez de la Parra, J. 1992: 199.

${ }^{51}$ Salmerón, P. 2013: 181.

${ }^{52}$ A modo de ejemplos, ver, Madre de Dios. 1984: 298, 300, 322, 332, 335; Gómez de la Parra, J. 1992: 167, 225, 252, 260-61, 265-66.

${ }^{53}$ Madre de Dios. 1984: 299.

${ }^{54}$ Madre de Dios. 1984: 299-302; Sigüienza y Góngora, C. 1683: 156, 160, 164v. Sigüenza y Góngora añade la recepción de un pedazo del velo de Teresa junto con el corazón.
} 
de Teresa en la cual se le explicaba cómo hacer y bendecir unos panecitos que servirían como «reliquias» para distribuir en la ciudad. Sin saber cómo cocer panes, las monjas los lograron perfectos y de entonces en adelante se hacían anualmente para distribución entre los devotos.$^{55}$ En la capital, por otra parte, hubo otro atentado fraudulento de usar panecitos para fomentar devoción a Santa Teresa. Aunque el llamado milagro popularizó el convento de San José poco después de su fundación, éste fue una patraña llevada a cabo por María de Poblete, hermana del deán de la catedral. Se suponía que la señora molía los panecitos que le traían los devotos, los echaba en una jarra de agua, y varias horas después los mismos resultaban restituidos íntegramente con la imagen de Santa Teresa. ${ }^{56}$ Este portento fue testimoniado por clérigos catedralicios, frailes carmelitas y elevados miembros de la sociedad novohispana. En 1677 fue verificado por el arzobispo-virrey Fray Payo de Rivera tras dictamen de una junta de teólogos. La aprobación oficial dio pie a sermones que comparaban la restitución de los panes a la resurrección y ponderaban la necesidad de guardar memoria de tales eventos. La orden del Carmelo recibía un espaldarazo muy deseable y Santa Teresa un homenaje espiritual que reforzaba su prestigio en el virreinato. También significó el apoyo financiero de varias figuras de la elite colonial. Entre ellos estaba el mercader Esteban de Molina Mosquera que sería el promotor del segundo convento carmelita en la capital.

A pesar del apoyo oficial al milagro de los panecitos varios sacerdotes detectaron irregularidades en el comportamiento de María Poblete y la denunciaron ante la Inquisición. Sin embargo, el proceso tropezaba con la previa aprobación del arzobispo y la publicidad que rodeaba la intervención de esa autoridad. A medida que se hicieron investigaciones los argumentos y testimonios en su contra, entre los que se encontraban los de varios Carmelitas, resultaban irrefutables. El tratamiento poco respetuoso de la Sra. llamaba la atención, reclamando que la santa se ausentaba y llamándola bellaca cuando no podía manipular los panecitos. A pesar de la intervención de la Inquisición no hubo ninguna condena del milagro. Es posible que el Santo Oficio no deseara revocar la opinión de un arzobispo. La Sra. Poblete murió en 1687 y la historia de los milagros se siguió

\footnotetext{
${ }^{55}$ Gómez de la Parra, J. 1992: 154-55. Las monjas poblanas tuvieron señales portentosas de cómo cortar las tocas de sus hábitos de modo correcto en una visión en la cual Santa Teresa se comunica con Ana de San Alberto, priora de Caravaca y le ruega envíe el modelo a las de Puebla. Madre de Dios. 1984: 298.

${ }^{56}$ Tenorio, Martha L. 2001. De panes y sermones: el milagro de las «panecitos» de Santa Teresa. México: El Colegio de México. Esta es la relación más completa del proceso de ratificación del «milagro» y el subsecuente cuestionamiento y proceso inquisitorial a que fue sometido. Ver también, Rubial García, A. y Díaz Nava, M ${ }^{a}$ de J. 2001. «La santa es una bellaca y nos hace muchas burlas.» El caso de los panecitos de Santa Teresa en la sociedad novohispana del siglo XVII», Estudios de Historia Novohispana, 53-75.
}

Hispania Sacra, LXVII

136, julio-diciembre 2015, 505-529 ISSN: 0018-215X, doi: 10.3989/hs.2015.015 
imprimiendo y recordando, mayormente por no desprestigiar a la santa entre los fieles, pero no hubo más milagros de panecitos en la ciudad de México.

La devoción al Cristo crucificado en la iglesia del convento de San José de México fue menos controvertida. Su linaje cristológico dio al templo y al convento una popularidad muy deseable en cuanto a fortalecer la aun joven comunidad.$^{57}$ El «milagro» fue la restauración por sí misma de un Cristo crucificado que había sido traído de España en 1545 y que ya para comienzos del XVII estaba abandonado y carcomido en una iglesia de un real de minas al norte de la capital. Hecha de papel y engrudo su deterioro era explicable y hacia 1615 el arzobispo Juan Pérez de la Serna, promotor del convento de San José en la capital, determinó que la imagen fuera destruida y enterrada. Durante cinco años no se llevó a cabo su orden y, al contrario, comenzaron a oírse ruidos y verse figuras de penitentes que desaparecían en la arruinada iglesia. En 1621 la imagen se descubrió completamente restaurada y sudorosa. Investigado el asunto el arzobispo ordenó trasladarla a la capital tras una estancia en el pueblo de Ixmiquilpan en el cual se repitieron los portentos. Pérez de la Serna donó la imagen a sus favorecidas Teresas. El Cristo estuvo situado por un tiempo cerca de las reliquias de un anacoreta muy venerado en México, Gregorio López, cuya beatificación fue promovida hasta finales del periodo virreinal. El Cristo recibió una nueva capilla en 1634, de nuevo reemplazada por una más suntuosa en 1684 pagada por el munificente patrón Esteban Molina Mosquera.$^{58}$ En realidad la veneración a Santa Teresa no pudo competir con la veneración novohispana hacia la virgen María, en sus encarnaciones marianas como la de Guadalupe, el Rosario y la Concepción. El culto de San José, propiciado por la misma Teresa también compitió con el propio. El culto teresiano fue más bien íntimo y personal entre sus seguidores y seguidoras, laicos y religiosos, y se manifestó en el respeto hacia la integridad de la orden en mantener su observancia claustral y espiritual. Las religiosas celebraban la fiesta anual de Santa Teresa con la apetecible pompa y la santa recibió la atención plástica que era de esperarse en el arte barroco novohispano. ${ }^{59}$

${ }^{57}$ Velasco, A. de. 1699. Renovación por si misma de la soberana imagen de Cristo Señor Nuestro Crucificado. México: María de Benavides. Reimpreso en México en 1858. Sigo la edición de 1858.

${ }^{58}$ Ramos Medina, M. 1990: 182-185.

${ }^{59}$ Salazar, Juan de. 1737. Vida del amor de Christo estampado en el corazón de Teresa. Sermón panegírico... en el convento de Carmelitas descalzas de esta ciudad de Puebla. Puebla: Viuda de Miguel Ortega. Ofrece una selección de pinturas y esculturas del convento de Puebla, así como retratos de monjas profesantes. Loreto, R (ed.). 2004. Una empresa divina. Las hijas de Santa Teresa de Jesús en América (1604-2004). Puebla: UDLA. Una pintura de un refectorio carmelita del siglo XIX es muy popular por ser tema poco común en la plástica mexicana. Ver, 1996. Pintura Novohispana. Museo Nacional del Virreinato. Tepotzotlan. México, INAH. 
Otra característica del barroco teresiano en México fue la ubicuidad de la actividad del demonio. El demonio fue un personaje presente en las reglas de la orden del Carmelo porque en el siglo XVI este personaje fue creciendo en estatura-quizás ayudado por la expansión de la imprenta y la inclinación a dramatizar las fuerzas del mal. El diablo y sus huestes existían para llevar a cabo su obra de contradecir la aspiración a la virtud de los miembros de la Orden, y también porque Dios permitía su existencia y acoso para acrisolar el carácter de sus seguidores. ${ }^{60}$ Teresa de Jesús creía en el demonio y lo respetaba, pero no se representó como víctima de sus fechorías. Al contrario, lo derrotó como adversario. ${ }^{61}$ Quizás una de las diferencias más notables entre Santa Teresa y sus seguidoras o intérpretes barrocos es la acrecentada presencia y acción del demonio en sus vidas y la enconada lucha que mantuvieron con las falanges demoníacas, resultando en un gran número de casos ser víctimas del «enemigo» común. Ya desde la Relación de Ana de Jesús, el demonio comienza a insinuarse como un personaje no sólo activo en sus tentaciones y contradicciones, sino como expresión de una fuerza brutal del mal que acosaba constantemente a las religiosas y desplegaba constantes asaltos que se cebaban en la carne y espíritu de las teresianas. ${ }^{62}$ Son abundantes las empresas del demonio en los conventos novohispanos y sus cronistas llenan sus narraciones de espeluznantes episodios, espejos de situaciones similares en la hagiografía peninsular. ${ }^{63}$ Las pocas citas directas de las religiosas novohispanas dejan ciertas dudas sobre las fronteras entre la experiencia personal y el mensaje favorecido por el cronista, pero no cabe duda de que existiera una base narrativa propia de la religiosa detrás del texto oficial. Según Gómez de la Parra, el demonio y sus huestes estaban dentro del convento como ladrones que intentaban robar a las religiosas de sus virtudes. ${ }^{64}$ Los ataques demoníacos no respetaban edad. En 1614 la madre María del Santísimo Sacramento, ya madre y abuela, profesa en Puebla a los 62 años decidida a seguir la Regla teresiana. Lamentablemente tuvo fuertes y terribles batallas con un rabioso demonio que «embravecido, dispuso amedrentarla con visiones horribles y espantosas figuras de fieras y animales que la hacían salir

\footnotetext{
${ }^{60}$ Regla y Constituciones de las religiosas carmelitas 1662, 325.

${ }^{61}$ Weber, A. 1992. «Saint Teresa. Demonologist», en Anne J. Cruz and Mary Elizabeth Perry, eds., Culture and Control in Counter-Reformation Spain: 171-195. Minneapolis: University of Minnesota Press.

${ }^{62}$ A modo de ejemplo, en Ana de Jesús, ver Howe, E.T. 2004: 51-54; Sánchez Lora, J.L. 1988 : 419-26.

${ }^{63}$ Cervantes, F. 1996. El diablo en el Nuevo Mundo: el impacto del diabolismo en la colonización de Hispanoamérica. Barcelona: Herder; Loreto López, R. 2002. «The Devil, Women, and the Body in Seventeenth-Century Puebla Convents», The Americas, 59:2, 181-199; Ayala Calderón, J. 2010. El diablo en la Nueva España: visiones y representaciones del diablo en documentos novohispanos de los siglos XVI y XVII. Guanajuato: Universidad de Guanajuato.

${ }^{64}$ Gómez de la Parra, J. 1992: 88.
} 
huyendo de la celda.» ${ }^{65}$ Pero quien más sufrió los embates del demonio fue la religiosa mejor conocida del convento poblano, Isabel de la Encarnación. ${ }^{66} \mathrm{Fr}$. Agustín de la Madre de Dios, un especialista en el lore diabólico también le dedicó varias páginas en su biografía de la monja. Isabel fue un personaje muy discutido dentro del convento y en la ciudad, ya que se le atribuyeron visiones en las que se exponían y condenaban los vicios de sus habitantes. Sus raptos, convulsiones y visiones le ganaron la desconfianza de autoridades eclesiásticas y fue sujeta a varios procesos de exorcismo bajo sospecha de estar obsesa. ${ }^{67}$ Los desmanes, malos tratamientos y persecuciones de los demonios se hacen palpables en la narración de Fr. Agustín: empellones, porrazos, golpes, vueltas en el aire, vueltas de la cabeza y otras contorsiones similares dejan al lector inmerso en un mar de angustias. El cuerpo vuelto campo de batalla era testimonio de la fortaleza de la mujer sufriente, que al fin se veía premiada cuando Dios terminaba sus pruebas. El concepto de un Dios que se aparta de quien lo ama y demanda más fatigas y pruebas para regresar bondadoso fue muy aceptable en el imaginario del siglo XVII. El premio a los sufrimientos personales y la victoria sobre las tentaciones fueron los favores recibidos: don de profecía, don de sacar almas del purgatorio, don de interpretar la escritura sagrada, don de leer almas. Resulta ser que la madre predicaba en sus arrobos y «solía explicárselas en nuestro castellano con raro magisterio, como lo pudiera hacer un doctor muy ilustrado. ${ }^{68}$ Esta sabiduría infusa si bien no comparable a la de Teresa la acercaba al modelo de la santa. Madre de Dios cita a un docto religioso de la Compañía de Jesús -que no podía ser otro que el padre Godínez-que estaba convencido que a través de la oración y los sufrimientos, Isabel de la Encarnación había llegado al conocimiento oscuro que purifica el alma y la llena de grandes luces. ${ }^{69}$ Isabel murió en 1636; su vida transcurrió cronológicamente bastante cerca del creciente auge teresiano. Tanto la protagonista como los testigos admiradores y hagiógrafos incondicionales, nos ponen frente al proceso de asimilación tanto personal como espiritual del ejemplo de Teresa y la voluntad de inscribirlo en la memoria de la comunidad virreinal y la comunidad teresiana universal. La maternidad de Teresa se expande a través de estas hijas que recrean a su modo la herencia de la madre con los cambios que son de rigor en el transcurso generacional. Implícitamente, esta y otras religiosas imitaban la vida de Santa Teresa, como nos explica Salmerón, que se tomó el trabajo de cotejar las devociones de Isabel de la Encarnación con las de Santa Teresa y otros santos

\footnotetext{
${ }^{65}$ Gómez de la Parra, J. 1992: 213. La madre murió a los 80 años.

${ }^{66}$ Salmerón, P. 2013: passim. Loreto López, R. 2006. «Oír, ver y escribir.» 190-92. Godínez fue padre espiritual de Isabel de la Encarnación y su transcripción de las batallas de Isabel con los demonios puede haber estado muy cerca de la narrativa confesional de la monja.

${ }^{67}$ Ramos Medina, M. 1997: 233-245.

${ }^{68}$ Madre de Dios. 1984: 334.

${ }^{69}$ Ibidem. 334-35.
} 
para corroborar las prácticas no solo de la religiosa sino del convento, donde se leían las obras de fray Juan de la Cruz y otros varones santos y la de María Vela a modo de protección contra los demonios. Singularmente esos libros se equiparaban a las reliquias en su valor de escudos físicos contra las fuerzas demoniacas. ${ }^{70}$

La trasmisión del carisma teresiano al nuevo mundo tuvo su primer ensayo en Nueva España. Los testimonios que quedan de esa transferencia cultural y espiritual indican que fue exitosa, especialmente en cuanto a establecer íntegramente el legado de observancia de las reglas y mantener la conexión con los propósito reformistas de la santa. Las Teresas novohispanas no solo respetaron sino vivieron la ascética de la pobreza dentro del convento, la oración mental y la interiorización de la devoción. Su agenda de promover la oración como defensa del catolicismo en riesgo en Europa actualizó el valor de la oración femenina como elemento necesario para el fortalecimiento de la religión católica a ambos lados del Atlántico y la lucha espiritual contra la herejía. La transverberación teresiana se convirtió en un emblema característico de la recepción del amor de Dios que centenares de imitadoras -no solo las Teresas- experimentaron en los siglo XVII y XVIII. En cierto modo las discípulas de las «fundaciones indianas», al experimentar y difundir la Regla teresiana satisficieron el ansia de viajar y rescatar almas que tuvo Teresa en su niñez.

\section{BIBLIOGRAFÍA}

Ayala Calderón, J. 2010. El diablo en la Nueva España: visiones y representaciones del diablo en documentos novohispanos de los siglos XVI y XVII. Guanajuato: Universidad de Guanajuato.

Borges, Fr. Pedro de. 1673. Sermón que predicó a la profesión de la madre María de la Encarnación, religiosa descalza del convento de Santa Teresa de Jesús de esta ciudad. México: viuda de Juan de Robles.

Cruz, Pablo de la. 1685. Recopilación sumaria de la historia de la Orden de Nuestra Señora del Carmen... con los de la reforma que hizo la santa Madre, seráfica virgen y mística doctora Santa Teresa de Jesús. Madrid: Bernardo de Villa-Diego.

Escritos de Santa Teresa. 1864. Vicente de la Fuente, ed. Tomo Primero. Madrid: M. Rivadeneira, Impresor.

Faci, R. A. 1761. Vida de la V. Mariana Villalba y Vicente y sus tres hijas Sor María, Sor Margarita y Sor Mariana de Escobar. Pamplona: Pascual de Ibáñez.

\footnotetext{
${ }^{70}$ Salmerón, P. 2013: 248-250. Isabel de la Encarnación tenía un libro de San Juan de la Cruz debajo de su almohada que se suponía le permitía escuchar las palabras del fraile, razón por la cual la atacaban los demonios para evitar la trasmisión.

Hispania Sacra, LXVII

136, julio-diciembre 2015, 505-529 ISSN: 0018-215X, doi: 10.3989/hs.2015.015
} 
Gante, Fr. Francisco Antonio de. 1719 Vida del Venerable padre Fr. Alonso de Orozco. Madrid Juan Sanz.

Gómez de la Parra, J. 1992. Fundación y primero siglo. Crónica del primer convento de carmelitas descalzas en Puebla, 1604-1704. México: Universidad Iberoamericana/ Comisión Puebla V Centenario.

Gómez, Fr Joseph, 1689. Vida de la venerable madre Antonia de san Jacinto... hija del real... convento de santa Clara de Jesús... de Querétaro. México: Imprenta de Antuerpia.

Herpoel, S. 1999. A la zaga de Santa Teresa : autobiografías por mandato. Amsterdam : Rodopi.

Howe, E. T. 2004. The Visionary Life of Madre Ana de San Agustín. Suffolk: Támesis.

Lanuza, Miguel Batista de. 1638. Vida de la bendita madre Isabel de Santo Domingo, compañera de Santa Teresa de Jesús. Madrid: Imprenta del Reino.

Lavrin, A.. 1995. «Espiritualidad en el claustro novohispano del siglo XVII», Colonial Latin American Review, 4:2, 155-180.

Lavrin, A. 1995. «De su puño y letra: Epístolas conventuales», en M. Ramos Medina, El Monacato femenino en el imperio español: 43-59. México: Condumex.

Lavrin, A. 1996. «La celda y el siglo. Epístolas conventuales», en M. Moraña (ed.) Mujer y cultura en la Colonia Hispanoamericana: 139-159. Pittsburg: Instituto Internacional de Literatura Iberoamericana, University of Pittsburg.

Lavrin, A. 1999. «La religiosa real y la inventada: diálogo entre dos modelos discursivos», en La Creatividad femenina en el mundo barroco hispánico. María de ZayasIsabel Rebeca Correa-Sor Juana Inés de la Cruz. Editado por Monika Bosse, Barbara Potthast y André Stoll. Kaseel: Edition Reichenberger.

Lavrin, A. 2005. «La madre María Magdalena Lorravaquio y su mundo visionario», Signos Históricos, 13: 22-41.

Lavrin, A. y Loreto López, R. (eds.) 2006. Diálogos espirituales. Manuscritos Femeninos Hispanoaméricanos, Siglos XVI-XIX, Puebla: UDLA.

Loreto López, R. 2002. «Escrito por ella misma. Vida de la madre Francisca de la Natividad», en A. Lavrin y R. Loreto, (eds.) Monjas y beatas. La escritura femenina y la espiritualidad barroca novohispana. Siglos XVII y XVIII. México: Universidad de las Américas, Puebla/ Archivo General de la Nación.

Loreto López, R. 2002. «The Devil, Women, and the Body in Seventeenth-Century Puebla Convents», The Americas, 59:2, 181-199.

Loreto López, Rosalva. Ed. 2004. Una empresa divina. Las hijas de Santa Teresa de Jesús en América (1604-2004). Puebla: UDLA.

Loreto López, Rosalva. 2006. «Oir, ver y escribir. Los textos hagio-biográficos y espirituales del padre Miguel Godínez. Ca 1630», en A. Lavrin y R. Loreto López (eds.) 
2006. Diálogos espirituales. Manuscritos Femeninos Hispanoaméricanos, Siglos XVIXIX: 156-200. Puebla: UDLA.

Madre de Dios, Fr. Agustín de la. 1984. Tesoro escondido en el Santo Carmelo Mexicano... Edición de Manuel Ramos Medina. México: Probursa/Universidad Iberoamericana.

Orozco, A. 1620. Confesiones del M.V.P Alonso de Orozco, de la Orden de San Agustín. Madrid: Viuda de Cosme Delgado.

Palafox y Mendoza, J. 1752. Obras, Tomo VII. Notas a las Cartas y Avisos de Santa Teresa de Jesús y varias poesías espirituales del venerable autor. Madrid: Imprenta de Gabriel Ramírez.

Pardo, F. 1676. Vida y virtudes heroicas de la madre María de Jesús, ... en el convento de la Limpia Concepción de la Virgen María... de los Ángeles... México: Viuda de Calderón.

Pintura Novohispana. 1996. Museo Nacional del Virreinato. Tepotzotlan. México, INAH.

Poutrin, I. 1995. Le Voile et la Plume. Autobiographie et Sainteté Feminine dans l'Espagne Moderne, Madrid: Casa de Velázquez.

Ramos Medina, M. 1990. Imagen de santidad en un mundo profano. México: Universidad Iberoamericana.

Ramos Medina, M. 1997. Místicas y descalzas. Fundaciones femeninas carmelitas en la Nueva España. México: Condumex.

Regla Primitiva de los religiosos descalzos de la Orden de Nuestra Madre Santísima... del Monte Carmelo de la Primitiva Observancia. 1788. Madrid: Imprenta de D. Joseph Doblado.

Rubial García, A y Díaz Nava, $M^{a}$ de J. 2001. «La santa es una bellaca y nos hace muchas burlas.» El caso de los panecitos de Santa Teresa en la sociedad novohispana del siglo XVII» Estudios de Historia Novohispana, 53-75.

Salazar, Juan de. 1737. Vida del amor de Christo estampado en el corazón de Teresa. Sermón panegírico...en el convento de Carmelitas descalzas de esta ciudad de Puebla. Puebla: Viuda de Miguel Ortega.

Salmerón, P. 1675. Vida de la Venerable Madre Isabel de la Encarnación. México: Francisco Rodríguez Lupercio. Edición de Robin Ann Rice, 2013. Madrid: Iberoamericana/Vervuert.

Sampson Vera Tudela, E. 2000. Colonial Angels. Narratives of Gender and Spirituality in Mexico, 1580-1750. Austin: University of Texas Press.

Sánchez Lora, J. L. 1988. Mujeres, conventos y formas de la religiosidad barroca. Madrid: Fundación Universitaria Española.

Sigüenza y Góngora, C. 1683. Parayso Occidental... México: Juan Rivera. 
Tenorio, M. L 2001. De panes y sermones: el milagro de las «panecitos» de Santa Teresa. México: El Colegio de México.

Teresa de Jesús, 1752. Libro llamado Camino de Perfección. En Obras de la Gloriosa Madre Santa Teresa de Jesús, Tomo I. Madrid: Joseph de Orga.

Teresa de Jesús. 1604. Libro llamado de las Moradas en Libros de la B. Madre Teresa de Jesús. Nápoles: Constantin Vidal.

Torres Villarroel, Diego de. 1798. Libro segundo. Vida ejemplar de la venerable madre Gregoria Francisca de Santa Teresa. Madrid: Imprenta de la Viuda «de Ibarra.

Velasco, Alonso A. de. 1699. Renovación por si misma de la soberana imagen de Cristo Señor Nuestro Crucificado. México: María de Benavides. Reimpreso en México en 1858.

Von Wobeser, G y Vila Vilar, E. (eds.). Muerte y vida en el más allá. España y América, Siglos XVI-XVIII. México: UNAM.

Von Wobeser, G. 2011. Cielo, infierno y purgatorio durante el virreinato de la Nueva España. México: UNAM/Editorial Jus.

Weber, A. 1992. «Saint Teresa. Demonologist.» En, Anne J. Cruz and Mary Elizabeth Perry, eds., Culture and Control in Counter-Reformation Spain. Minneapolis: University of Minnesota Press, 171- 195. 